\title{
FULL-SCALE PROTOTYPE OF AN OVERTOPPING BREAKWATER FOR WAVE ENERGY CONVERSION
}

\author{
Pasquale Contestabile ${ }^{1}$, Vincenzo Ferrante ${ }^{1}$, Enrico Di Lauro ${ }^{1}$ and Diego Vicinanza ${ }^{1}$
}

\begin{abstract}
The Overtopping BReakwater for Energy Conversion (OBREC) is a new typology of overtopping wave energy converter (OTD) integrated into a traditional rubble mound breakwater. The device can be considered as an innovative non-conventional breakwater that has the same functions as the traditional structures with the addedvalued of the energy production. The paper presents a comprehensive overview of the OBREC, offering a synthesis of the complete design process, from the results of the two complementary test campaigns in small scale carried out in 2012 and 2014 at Aalborg University, to the description of the full-scale device installed in Naples in 2016. The device represents the first OTD device in full-scale integrated into an existing rubble mound breakwater and it has been equipped by an instrumental apparatus to measure its response to the wave interaction. The monitoring of the full-scale device in the port of Naples, particularly during storm conditions, is aimed to study the scaling effects in wave loading and the overall performance of this breakwater-integrated OTD, included performance in terms of the energy production.
\end{abstract}

Keywords: OBREC; innovative breakwater; overtopping wave energy converter; full-scale device

\section{INTRODUCTION}

There is a global necessity for low carbon power, and the ocean renewable energy could make an important support to the emission targets as well as providing a high-technology industry. The idea of extracting energy from ocean waves is not recent, and the first patent of a device design to use ocean waves to generate power has been proposed in the early $18^{\text {th }}$ century (Burman and Walker, 2009). Nevertheless, only during the last twenty years, scientists and researchers have been deeply involved with the development of new original technologies able to exploit energy from the sea. The extracted energy is generally converted into electrical energy, and these innovative devices are commonly denominated Wave Energy Converters (hereafter WECs). Although more than 1000 WECs have been patented worldwide (Falcão and Henriques, 2016), this technology is currently in an early stage of development. A serious break on the growth and commercialization of these devices are their costs, still very high when compared with other more established renewable energy technologies such as wind turbines or solar panels, and their potential environmental risks (Azzellino et al., 2013). Other important constraints are the operational efficiency and the structural survivability of the devices, nowadays still low considering that several devices have been partially or, even more, completely destroyed during extreme storms (Medina-Lopez et al., 2015; Falcão and Henriques, 2016).

Recently, a novel idea has been proposed to reduce the costs of the WECs and at the same time to increase their reliability, consisting in integrating the devices into coastal defense structures such as rubble mound breakwaters or vertical structures. These non-conventional breakwaters would still have their principal function of sheltering a location from the action of harmful sea dynamics, but with an important added-value from the presence of the integrated WEC able to exploit part of the energy from the incoming waves. This new way to conceive the coastal structures with WECs embedded into them could be the real driving force behind the economic growth of the entire marine renewable energy sector. Integrating a WEC into new breakwater has several advantages such as the low construction costs, considering that the breakwater would be built regardless of the inclusion of the wave energy converter (cost-sharing). Furthermore, the access for the construction and maintenance of the WEC is much easier. For these reasons, the integration is probably the best solution for the shoreline WEC from the economical, constructional and operational point of view. Naturally, the energy extracted with this new technology is lower compared with devices located in deep sea and, certainly, not all breakwaters are suitable for the integration considering their type, geographical location and orientation with respect to the incident waves.

Although the first example of this technology has been proposed in the early 1990 in Japan at the port of Sakata (Takahashi et al., 1992), at the time of writing this paper, only three devices of WECs integrated into breakwaters are currently in operation, all located in Europe. The first two devices

\footnotetext{
${ }^{1}$ Department of Civil Engineering, Design, Building, and Environment, University of Campania “Luigi Vanvitelli", Caserta 81100, Italy.
} 
consist both of an oscillating water column (OWC) systems integrated into vertical breakwaters situated at the port of Mutriku in Spain (Torre-Enciso et al., 2009; Torre-Enciso et al., 2009) and the port of Civitavecchia in Italy (Arena et al., 2013).

The most recent full-scale device of WEC embedded intro a rubble mound breakwater has been installed at the port of Naples (Italy) in 2015 (Contestabile et al., 2016). The prototype represents the first non-conventional breakwater in the world which exploits the overtopping phenomena in order to capture energy from waves and to convert it into electricity. The goal of this paper is to present a wide overview of the OBREC (Overtopping BReakwater for Energy Conversion), offering a synthesis of the entire design process, from the results of the physical model tests in small scale to the description of the prototype in Naples.

\section{THE OBREC TECHNOLOGY}

The idea of integrating an overtopping device (OTD) into a breakwater is not new. First studies on this particular typology were started as of 2004, when a Norwegian company (WAVEenergy AS) was founded to develop a pilot project of a device called Seawave Slot-Cone generator (SSG). It is an overtopping wave energy converter which utilizes three reservoirs placed on top of each other. Two pilot plants were planned to be installed during 2008 at small islands near Stavanger (Norway). Unfortunately, environmental issues required locating the SSG pilots to another location, but, after more than ten years, these projects have not been realized. Although several studies (Kofoed, 2002; Margheritini et al., 2009) suggest that the use of multiple reservoirs improve the efficiency compared to structures with one reservoir, on the other hand, this complex geometry leads the device to be still not economically competitive with respect to other WECs embedded into breakwater.

Moving from the recent intense research on the SSG (Buccino et al., 2012; Buccino et al., 2015a; Buccino et al., 2015b; Oliveira et al., 2016), a slightly different device, denominated Overtopping BReakwater for Energy Conversion (OBREC), is under development (Vicinanza et al., 2013a; Vicinanza et al., 2014, Contestabile et al., 2017a). It is an innovative breakwater with a special shape designed to accommodate an overtopping wave energy converter (OTD) and all the instrumental equipment for the energy conversion. The device has been developed by the Research team of the University of Campania and it consists of a concrete structure with a front planar ramp and just one reservoir located immediately behind it, whose bottom is situated above the sea water level (Fig. 1). This technology can capture part of the energy from incident waves that overtop the frontal ramp. The potential energy of the water stored in the reservoir is then converted into kinetic energy, flowing through low-head turbines located in a machine room behind the reservoir. The energy is thus converted into electrical energy by means generators coupled to the turbines.

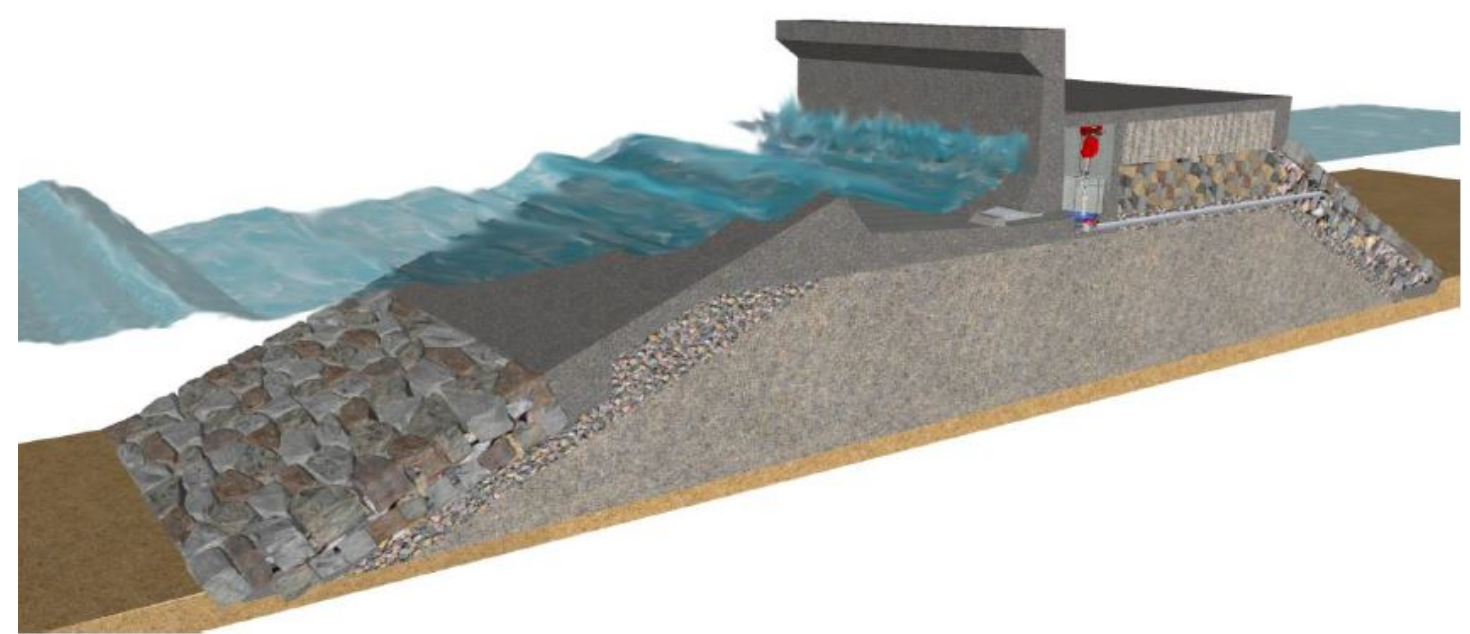

Figure 1. Conceptual design of the OBREC

Several case studies have been analyzed, making the hypothesis of the extension of existing traditional breakwaters with this innovative embedded WEC technology, and satisfactory results have been found. An application study has been investigated, for example, along the coast of Santa Catarina in Brazil, which represent one of the most favorable regions in the Atlantic Ocean for the OBREC, 
mostly for the low seasonal variability, the very low occurrence of calm sea state and few extreme annual storms (Contestabile et al., 2015). The annual average wave energy flux along the coast of this area has been computed in $14 \mathrm{~kW} / \mathrm{m}$ and, in the hypothesis of an extension of $500 \mathrm{~m}$ of the existing breakwater, the technology would generate $3500 \mathrm{MWh}$ of energy, which provides the household consumption for $\sim 6500$ habitants. An economical assessment of the OBREC, in terms of financial returns, has been also described for mild and high energetic coastal area such as the southwest of the Australia (Contestabile et al., 2017b). A specific technique has been also presented to give an estimation of the quality of the investments, evaluating different turbine strategy layouts and comparing the costs of the device with those of conventional rubble mound breakwaters.

\section{MAIN RESULTS OF MODEL SCALE TEST}

The geometrical optimization of the OBREC has required two complementary model test campaigns, both conducted in 2012 and 2014 at the laboratory of the Department of Civil Engineering of the Aalborg University in Denmark. The research has been carried out on small scale (Froude scaling 1:30) and has been aimed to measure the pressure exerting on the device and to evaluate the hydraulic processes such as the reflection and the overtopping at the rear side of the structure and the volume of water into the reservoir. The measure of the mean overtopping discharge into the reservoir for different sea state conditions has been used to estimate the potential wave energy that can be extracted from this hybrid WEC.

\section{Campaign test AAU2012}

The first test campaign (AAU2012) was conducted with the aim to compare and evaluate the difference between the OBREC and a traditional rubble mound breakwater with a crown wall on the top (Vicinanza et al., 2014). In order to estimate the functionality of the OBREC as a coastal structure defense, two main parameters were evaluated: the reflection coefficient and the overtopping at the rear side of the structure. Regarding this essential comparison, the main results obtained from the AAU2012 can be summarized as follows:

- The reflection coefficients are comparable, or even lower, to those measured for traditional structures, although the smooth ramp of the OBREC offers a weak contribute in terms of wave dissipation when compared with the permeable armor layer of a conventional breakwater. The reason can be addressed due to the presence of the reservoir behind the ramp in which waves are captured, losing a large part of their energy.

- The overtopping at the rear side of the OBREC has been dramatically reduced $(\sim 80 \%)$ due to the inclusion of a triangular parapet located on the top of the crow wall of the OBREC. With the triangular nose, the mean overtopping discharge behind the vertical wall is lower also compared to the traditional breakwater, which means that, with the same tolerable mean overtopping, the OBREC can be designed with a crest height lower than a conventional structure.

These two important results, after the test AAU2012, led to the conclusion that the integration of this innovative OTD device into an existing or new breakwater does not change its primary function of harbor defense from wave motion. Moreover, in some cases, the integration can also improve the general hydraulic response of the coastal structure. After the campaign test in 2012, tentative design formulas have been proposed to evaluate the reflection and the overtopping at the rear side of the structure and into the reservoir. Further design formulas have been also presented to estimate the resultant forces acting on the different part of the device since the application of the existing formulas from literature is not suitable to the OBREC due to its particular geometrical shape (Vicinanza et al., 2014).

\section{Campaign test AAU2014}

In order to have an accurate compression of the complex phenomena of the wave-OBREC interaction finding the optimal geometrical configuration, new tests have been performed in 2014. The goal has been to understand the influence of some geometrical parameters, such as the horizontal reservoir width and frontal ramp shape and length, on the hydraulic performance. The real challenge was to increase the wave overtopping into the reservoir without increasing the reflection coefficient and the crest of the structure. For this reason, in the test campaign carried out in 2014 (AAU2014) two different shapes of the front ramp (planar and curved) have been simultaneously analyzed and, for the two configurations, three different reservoir widths and different still water levels have been configured.

Results (Iuppa et al., 2016) showed a slight reduction ( 20\%) of the mean water discharge in the front reservoir and at the rear side of the structure for the configuration with curved ramp compared 
with planar ramp. The device with a planar ramp, although would lead to higher crest of the vertical wall in the design process, has a higher performance in terms of energy production of the system. However, because the safety level could be increased by using a wider front reservoir, the flat configuration seems to be the most preferable for future full-scale devices, also for an economical and construction point of view.

Design formulas have been provided by Iuppa et al. (2016) taking into account the effect of the new geometrical parameters analyzed in test AAU2014. A synthesis of the hydraulic formulas for the configuration with planar ramp is here presented, while the results regarding the wave loading acting on the device and the design formulas are given in Contestabile et al. (2017a).

The mean wave discharge at the rear side of the OBREC, $q_{\text {rear }}$, can be estimated applying the following formula:

$$
\frac{q_{\text {rear }} \cdot T_{m-1,0}}{L_{m-1,0}^{2}}=0.0139 \cdot \exp \left(-7.17 \cdot X_{\text {rear }}\right)
$$

where $T_{m-1,0}$ is the mean spectral wave period at the toe of the structure and $L_{m-1,0}$ is the deep water wave length using $T_{m-1,0}$. The parameter $X_{\text {rear }}$ in Eq. (1) is defined by the following relation:

$$
X_{\text {rear }}=\left(\frac{R_{c}}{H_{m 0}}\right) \cdot\left(\frac{\Delta R_{c}}{d_{w}}\right)^{0.25} \cdot\left(\frac{\Delta B_{r}}{B_{r}}\right)^{0.5}
$$

in which $H_{m 0}$ is the significant wave height at the toe of the structure, $R_{c}$ is the crest freeboard of the crown wall, $\Delta R_{c}$ is the vertical distance between the crest ramp and the crest wall, $d_{w}$ is the height of the frontal ramp, $\Delta B_{r}$ is the horizontal distance between the crest of the ramp and the wall, and $B_{r}$ is the horizontal reservoir width.

The wave overtopping into the reservoir, $q_{\text {res }}$, can be evaluated using the formula from EurOtop Manual (EurOtop, 2007) using the probabilistic approach:

$$
\frac{q_{r e s}}{\sqrt{g \cdot H_{m 0}^{3}}}=0.2 \cdot \exp \left(-2.6 \frac{R_{c}}{H_{m 0} \cdot \gamma_{f} \cdot \gamma_{\beta} \cdot \gamma_{b}}\right)
$$

where $\gamma_{f}$ is the reduction factor due to the roughness and permeability of the slope, $\gamma_{\beta}$ is the reduction factor in the case of oblique wave attack and $\gamma_{b}$ is the influence factor for the presence of a berm. The relations for $\gamma_{\beta}$ and $\gamma_{b}$ can be found following the instructions presented into the EurOtop (EurOtop, 2007). Regarding the parameters $\gamma_{f}$, due to the configuration of the device with a smooth impermeable ramp only located on the higher part of the armor layer, a new formula is proposed by Iuppa et al. (2016):

$$
\gamma_{f}=\left\{\begin{array}{cl}
\tanh \left(7.47\left(\frac{d_{d}}{L_{m-1,0}}\right)^{0.42}\right) & \text { if } \frac{d_{d}}{L_{m-1,0}}>0.006 \\
0.7 & \text { if } \frac{d_{d}}{L_{m-1,0}} \leq 0.006
\end{array}\right.
$$

in which $d_{d}$ represents the height of the submerged sloping ramp.

Finally, the reflection coefficient of the OBREC, $K_{r}$, can be evaluated with the following formula (Zanuttigh and van der Meer, 2008):

$$
K_{r}=\tanh \left(a \cdot \xi_{m-1,0}^{b}\right)
$$

where $\xi_{m-1,0}$ is the breaking parameter referenced to $T_{m-1,0}$ and the parameters $a$ and $b$ are defined as:

$$
a=0.167\left(1-\exp \left(3.2 \cdot \gamma_{f, K r}\right)\right)
$$




$$
b=1.49\left(\gamma_{f, K r}-0.38\right)^{2}+0.86
$$

Iuppa et al. (2016) proposes a relation for the coefficient $\gamma_{f, K r}$, slightly different than that proposed by Zanuttigh and Van der Meer (2008), and evaluated as:

$$
\gamma_{f, K r}=c_{\not f} \cdot \gamma_{f}
$$

in which $\gamma_{f}$ is the parameter already presented in Eq. (4) and the corrective coefficient $c_{y f}$ is evaluated with the following relation:

$$
c_{\gamma f}=\tanh \left(2.64 \cdot\left(\frac{R_{r}}{H_{m 0}} \frac{d_{d}}{L_{m-1,0}}\right)^{0.28}\right)
$$

where $R_{r}$ represents the crest freeboard of the frontal ramp. The parameters considered in the above relations are showed in Fig. 2.

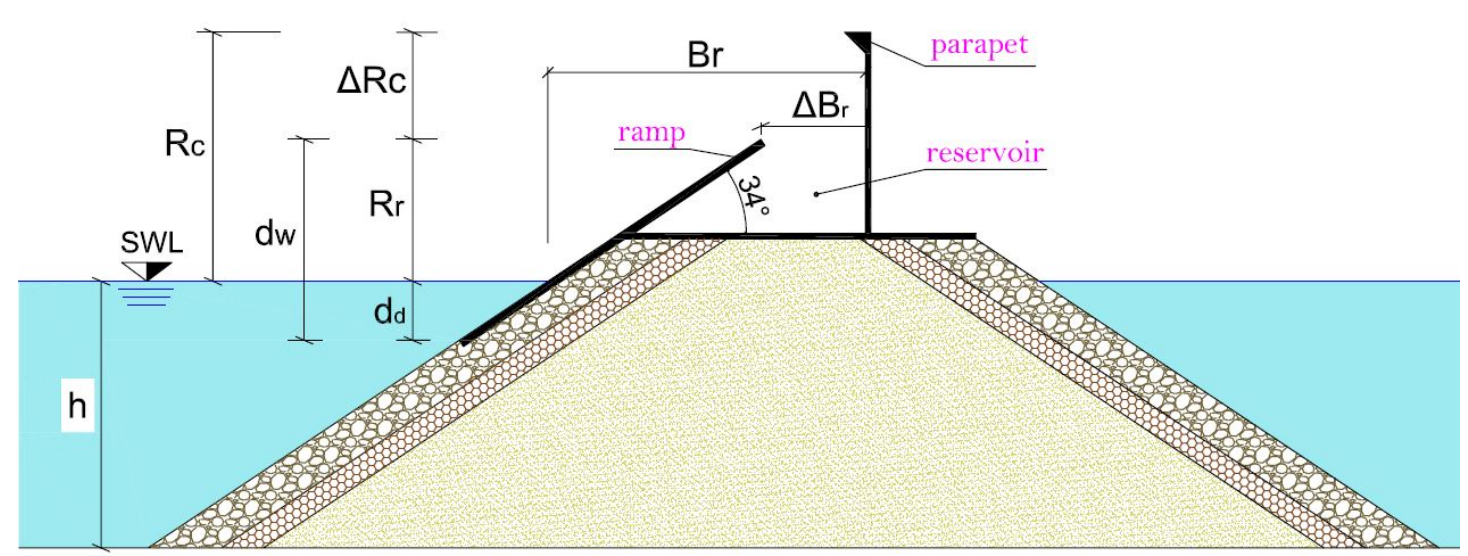

Figure 2. Cross section of the OBREC with the main geometrical parameters

Although the physical modeling in a laboratory is still the key in the design of coastal structures, it is worth considering that the use of the models in small scale for complex structures is not always sufficient to obtain the complete structural response of a marine structure. For example, during violent wave impacts with very short duration, the compressibility of the air pocket can strongly influence the magnitude of the generated pressure, thus the local pressure can not be simply scaled by Froude. It is widely believed that in these cases the Froude scaling law can cause a significant overestimation of the impact pressures. Considering the non-conventional geometry of the OBREC, research work into aeration, local effects and extreme wave events on a full-scale device have been considered essential to have a complete knowledge of the overall wave-structure interaction phenomena. However, the relations presented in this paper for the hydraulic response of the device and the results on loading acting on the OBREC from test AAU2014 (Contestabile et al., 2017a) and from Allsop et al. (1997) have been used to design the device in full-scale at the port of Naples in Italy.

\section{THE OBREC PROTOTYPE AT THE PORT OF NAPLES (ITALY)}

The full-scale device of the OBREC has been installed in 2015 in the port of Naples (Italy) along 6 $\mathrm{m}$ of the San Vincenzo rubble mound breakwater (Fig. 3). The depth at the toe of the structure is $25 \mathrm{~m}$. The area where the OBREC has been installed has a mean yearly wave power of $\sim 2.5 \mathrm{~kW} / \mathrm{m}$ (Contestabile et al., 2016) considering wave data provided by the ECMWF (European Centre for Medium-Range Weather Forecasts). It is important to point out that for future estimation on energy production, it becomes imperative to have a more accurate and complete wave energy assessment of the interested area. Therefore, further studies with numerical models calibrated with wave data measured with buoys are required to identify with more detail the energy potential at the gulf of Naples. The mean wave power is rather very low if compared to the $11 \mathrm{~kW} / \mathrm{m}$ on the northwest of the Sardinia in Italy (Vicinanza et al., 2011; Vicinanza et al., 2013b) or even more if compared to the $60-70 \mathrm{~kW} / \mathrm{m}$ on the Atlantic European coasts (Mørk et al., 2010; Gunn and Stock-Williams, 2012). The Tyrrhenian Sea 
and, still more, the protected gulf of Naples have very long periods of calm sea states (significant wave height $H_{m 0}$ lower than $0.5 \mathrm{~m}$ ) during the year, and important seasonal variability of the wave conditions. Despite what one may think, these aspects can be considered positive for this stage of development, allowing to safely operate during the maintenance activities and the installation of the instrumental equipment for the monitoring of the prototype. On the other hand, being the structure placed on intermediate depth, no depth breaking conditions occur, also for extreme storms. It means that the pilot is exposed to important environmental conditions if compared to other hybrid WEC located in shallow water. This leads to the conclusion that the real challenge of the OBREC monitoring in full-scale installed in the port of Naples is to demonstrate the feasibility, structural relatability and to evaluate the overall performances, particularly during the storm conditions. The purpose is to acquire data during the (sporadic) storm events in this area, using the pilot plant as a large natural laboratory in which the experimental data are collected and analyzed for further future applications in the more energetic and exposed coastal areas.

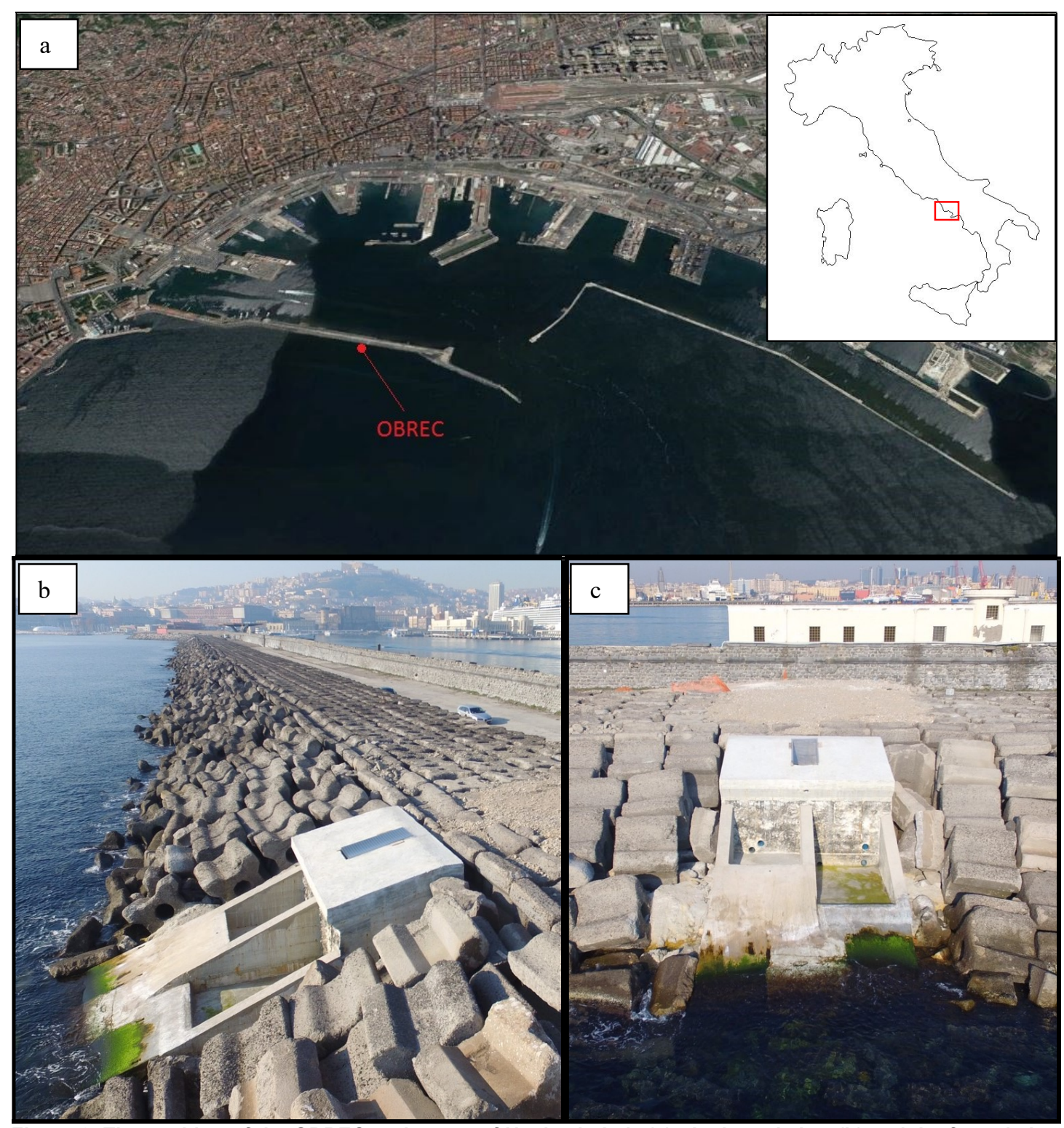

Figure 3. The position of the OBREC at the port of Naples in Italy (a); the lateral view (b) and the frontal view (c) of the device installed in the San Vincenzo breakwater. 


\section{Geometry and materials}

The pilot plant of the OBREC has been installed replacing part of the armor layer of the San Vincenzo breakwater, for an area of $\sim 75 \mathrm{~m}^{2}$. The armor layer of the original breakwater has a slope of $1: 2$ and it consists of concrete cubic armor units denominated Antifers, having the dimension of $2 \mathrm{~m}$ and the weight of $\sim 12$ tons. The OBREC has a length of only $6 \mathrm{~m}$ and it is installed almost in the central part of the San Vincenzo breakwater, next to an existing building situated behind the breakwater (Fig $3 c$ ). This building is used as a laboratory hub for scientists and researchers for the monitoring of the OBREC during storm conditions. Figs. $3 b$ and $3 c$ show respectively the lateral and frontal views of the device. This hybrid WEC consists of two adjacent configurations denominated RS-Lab (Real Scale Laboratory) and NW-Lab (Natural Waves Laboratory). As can be seen from Fig. 4, the main difference between the two configurations is the crest freeboard of the frontal ramp, whose value is for the $R S-L a b$ and the $N W$-Lab respectively $1.70 \mathrm{~m}$ and $1.00 \mathrm{~m}$. The other important difference between the $R S-L a b$ and $N W$-Lab configuration is the horizontal reservoir width, which measures respectively $2.5 \mathrm{~m}$ and 3.7 $\mathrm{m}$. These two configurations would help to better understand the complex wave-structure interaction of the prototype since the $R C-L a b$ is the optimal configuration for the low energetic site condition, while the $N W-L a b$ is considered in the analysis as a large scale model suitable for more energetic coastal areas.

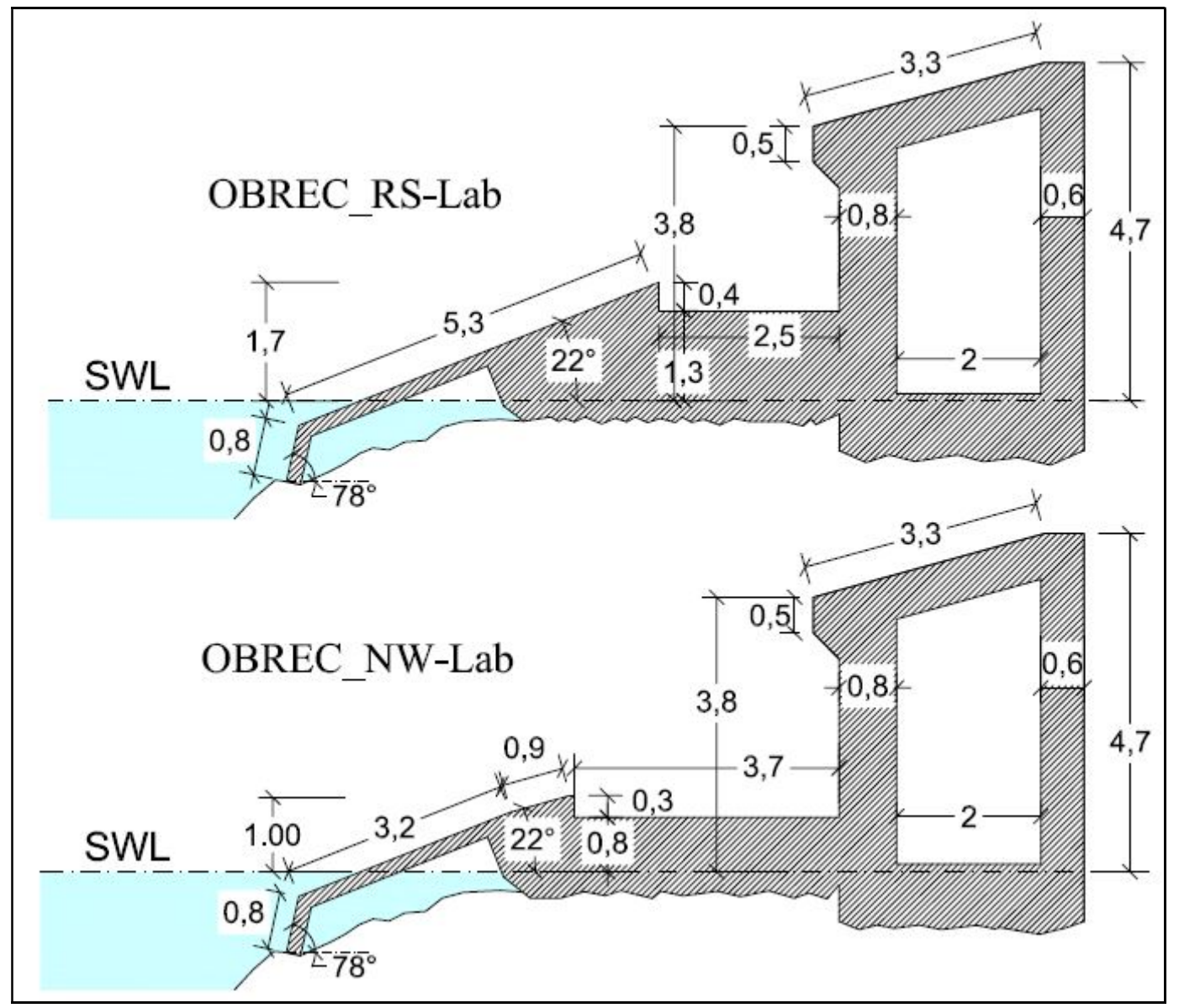

Figure 4. Cross sections of the two configurations of the OBREC at the port of Naples (Italy).

Both configurations consist of a frontal planar ramp with a slope of $22^{\circ}$ compared to the horizontal. The ramp is made by three units of precast concrete structures with a thickness of $20 \mathrm{~cm}$, located adjacent to each other and integrated into the base reservoirs, lying immediately behind them.

The reservoirs of the two adjacent configurations consist of a concrete slab foundation with different thickness and 12 micropiles with a length of $10 \mathrm{~m}$ and a diameter of $300 \mathrm{~mm}$. The nonconventional installation of a slab foundation with ground anchoring system using micropiles is justified by the need to significantly increase the stability of the pilot plant, ensuring high safety coefficients compared to the traditional design of coastal structures. 
The reservoirs are separated by a central vertical wall (Fig. 3b) which follows the same inclination of the frontal ramp. Behind the reservoirs, a machine room with an internal area of $11.4 \mathrm{~m}^{2}$ has been built in situ. This machine room accommodates the entire instrumental apparatus used for the OBREC monitoring. On the top of the seaward vertical wall of the machine room, a triangular parapet has been installed. This structure, denominated nose, has a slope of $45^{\circ}$ compared to the vertical and it has aimed to reduce the water discharge at the rear side of the WEC, as demonstrated by Vicinanza et al. (2014) and by authors (Kortenhaus et al., 2003; Pearson et al., 2004; Van Doorslaer and de Rouck, 2011) who conducted tests on conventional breakwaters and seawall.

For further information and details on the geometrical configuration of the full-scale device, materials and the different steps of the construction process, please refer to Contestabile et al. (2016).

\section{Instrumentation}

The full-scale device has been equipped with an instrumental apparatus aimed to measure the overall performances of the device, included the performances in terms of energy production.

Precisely, an innovative small and efficient wave buoy, denominated Directional Wave Spectra Drifting Buoy (DWSDB) has been moored at a distance of 100 meters in front of the prototype in order to measure the incident waves acting on it. The DWSD-buoy uses the GPS technology developed by the Lagrangian Drifter Laboratory (LDL) of the Scripps Institution of Oceanography (SIO). It measures the waves for $\sim 17$ min every hour and transmits the computed spectra of each seas state via the Iridium Satellite system. All the principal wave parameters and the wave spectra are thus accessible in real time on a dedicated website. This technology, applied to the monitoring of a full-scale WEC, offers many advantages, both practical and economic. The use of a GPS receiver results not only very cheap, but it allows also the development of small buoys, which can be easily transported and installed by hand from a small vessel. The buoy has, in fact, a diameter of $39 \mathrm{~cm}$ and a weight of $12 \mathrm{~kg}$ (Fig. 5). The reduced dimension offers also the advantage to cope higher wave frequency, extending the measurement range of these instruments. Furthermore, there are no mechanical moving parts or accelerometers into the GPS-based buoy that would require delicate maintenance, thus the system does not need any calibration. All the wave data currently gathered by means the GPS-buoy will also be used to improve the reliability of wave forecasting as well as to calibrate and validate the numerical models for a detailed wave energy site assessment in this coastal area.

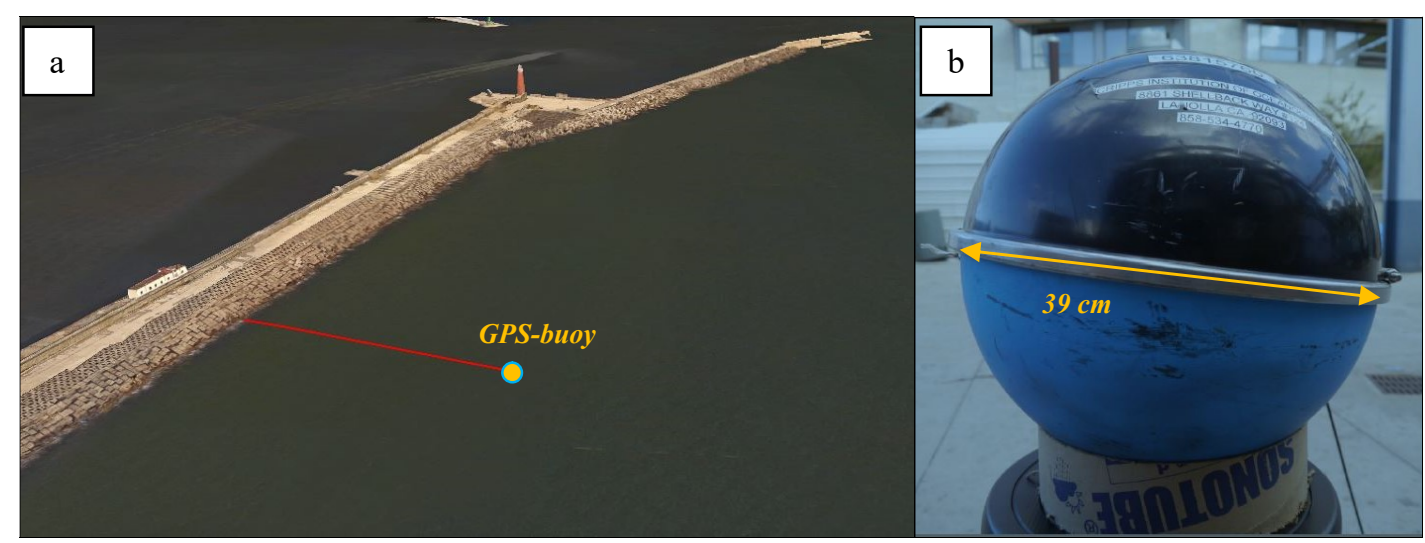

Figure 5. The position of the GPS-buoy in front of the OBREC (a) and a detail of the instrument (b).

The wave pressure exerting on the OBREC is measured by 8 pressure transducers located on the different parts of the device. Currently, the wave pressure data are gathered only for sea state with significant wave height greater than 1 meter (Fig. 6). The aim is to acquire and analyze pressure data to compare it with existing formula in literature and validate pressure data measured in the experimental test in small scale in 2012 (Vicinanza et al. 2014) and in 2014 (Contestabile et al, 2017a). Two highresolution cameras are used to capture the wave profile when waves overtop the ramp and impact on the vertical wall. The coupled analysis of the pressure transducers and the cameras will provide details on the hydrodynamic behavior and the interaction wave-structure in order to have a better understanding of the distribution of the pressures acting on the prototype, as well as on the identification of the shape that the wave surface can take before the ramp and in front of the vertical wall of the OBREC. 
Three fixed-Kaplan (propeller) low-head turbines equipped with permanent magnet generators and a maximum-power-point-tracking charge controller are located in the machine room. The total power of the turbines currently installed is $2.5 \mathrm{~kW}$. The goal for the coming months is to install a set of different low-head turbines, including an innovative hybrid "multi-field turbine" obtained coupling different typology of turbines (Contestabile et al., 2016). The purpose of the monitoring is to test several different turbines in order to identify the best technology for this hybrid WEC via cost-benefit analysis.

The overtopping rate in the front reservoirs is calculated by measuring the variation of the water depth in small steel boxes placed in the machine room. The water stored in the two reservoirs flows into these boxes via five circular pipes located in the frontal vertical wall of the machine room (Fig.3c).

Finally, it is expected also to perform measurements of the overtopping volume at the rear side of the structure following the techniques successfully used in past for the monitoring of traditional breakwater and seawalls (Herbert 1995; Troch et al., 2004; Briganti, 2005; Pullen et al., 2009). In this regard, a collecting steel tank behind the local pilot plant machines equipped with level probes in planned to be installed the next months. The measurement of water level variation inside the tank by means of wave gauges will allow calculating the individual overtopping volumes and thus the mean overtopping discharge during extreme storms.

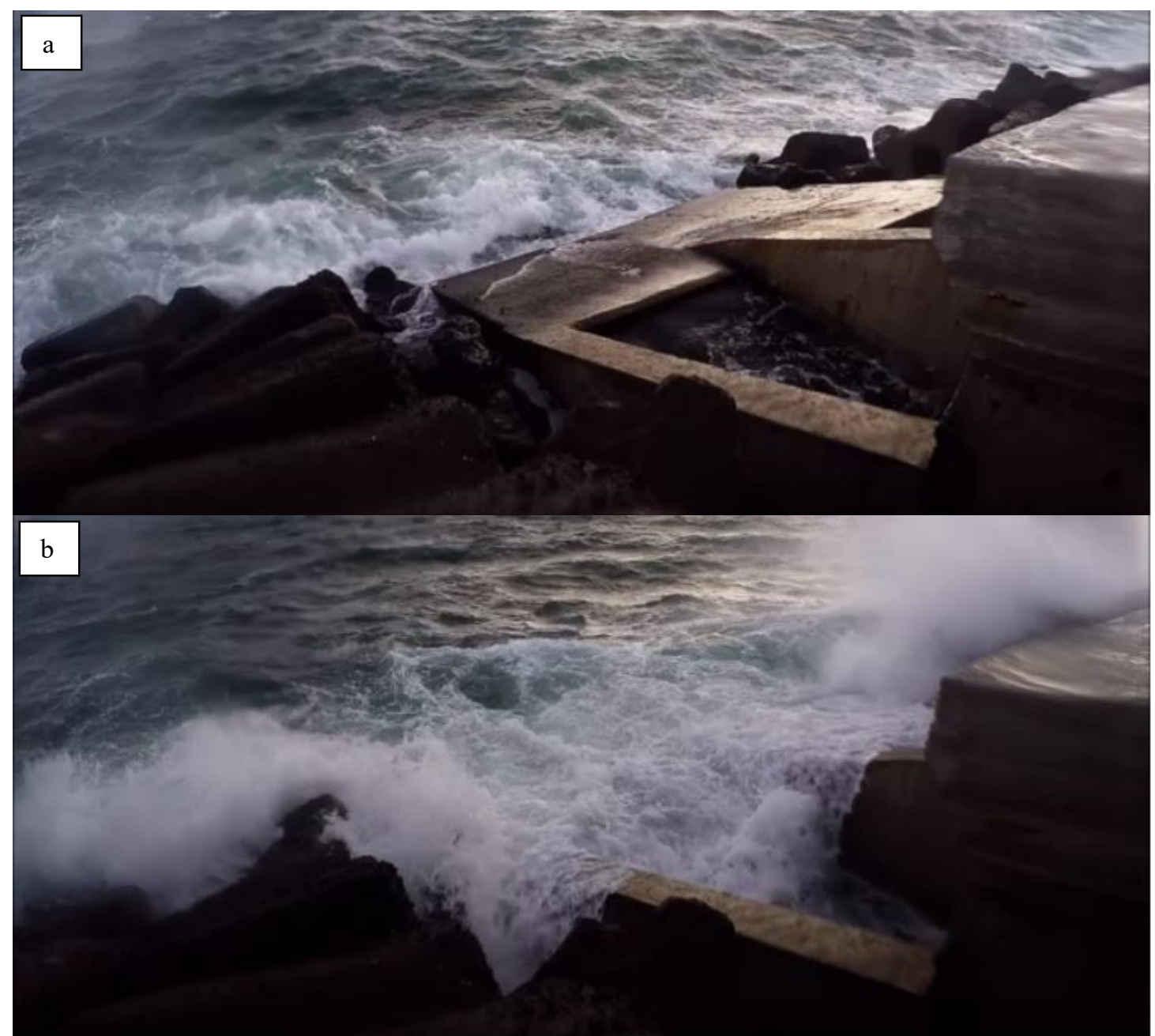

Figure 5. Wave run-up over the ramp (a) and wave overtopping on the frontal reservoir (b) of the OBREC during a wave storm in 2016.

\section{CONCLUSIONS}

The paper offers an overview of the last years of research work on a breakwater combined with an overtopping wave energy converter, denominated OBREC (Overtopping BReakwater for Energy Conversion). Two complementary test campaigns in small scale have been conducted in 2012 and 2014 at the Aalborg University and the significant results are summarized in the paper. The physical model 
tests carried out on the OBREC allowed to better understand the hydraulic processes of the wavestructure interaction and to investigate the influence of the geometrical and hydraulic parameters on the overtopping phenomena and wave reflection, as well as the pressure distribution along the structure during extreme wave conditions. Additionally, the paper presents the empirical relations to predict the mean discharge water volume at the rear side of the device, the overtopping into the frontal reservoirs and the reflection coefficient. These formulas, including the relations to predict the wave loading acting on the device, have been used to design the first full-scale device of this new overtopping WEC integrated into an existing rubble mound breakwater. Specifically, the device is has been installed in 2015 at the Naples harbor in Italy. The paper describes the two different geometric configurations of the full-scale device, giving also an overview of the instrumental equipment currently installed for the field monitoring on the OBREC during storm conditions. The monitoring of the OBREC at the port of Naples will provide all the information needed for better understanding of the hydraulic process of wave-structure interactions, as well as the capacity to convert part of the energy form the incoming waves into electricity. In this direction, significant results are expected from the field measurements of the low-head hydraulic turbines, since for the first time the performance of different types of turbines applied to an overtopping WEC integrated into breakwaters are simultaneously compared.

\section{ACKNOWLEDGMENTS}

The work discussed here is part of the National Operational Programme for "Research and Competitiveness" 2007-2013 (NOP for R\&C) founded project PON04a3_00303 titled "DIMEMODIga Marittima per l'Energia del Moto Ondoso" (Maritime Breakwater for Wave Energy Conversion), Project PON04a3_00303. The work was also partially supported by the RITMARE Flagship Project. Authors gratefully acknowledge the Italian Ministry of Education, University and Research (MIUR) for supporting this innovative research and the University of Campania "Luigi Vanvitelli" for encouraging mobility of researchers.

\section{REFERENCES}

Allsop, N.W.H., J.E. McKenna, D.Vicinanza, and T.T.J. Whittaker. 1997. New design methods for wave impact loadings on vertical breakwaters and seawalls, Proceedings of the $25^{\text {th }}$ International Conference on Coastal Engineering, 2, pp. 2508-2521.

Arena, F., A. Romolo, G. Malara, and A. Ascanelli. 2013. On design and building of a U-OWC wave energy converter in the Mediterranean Sea: a case study, Proceedings of the $32^{\text {nd }}$ International Conference on Ocean, Offshore and Arctic Engineering, Nantes, France.

Azzellino, A., D. Conley, D. Vicinanza, and J. Kofoed. 2013. Marine Renewable Energies: Perspectives and Implications for Marine Ecosystems, Scientific World Journal, vol. 2013, 547563.

Briganti R., G. Bellotti, L. Franco, J. De Rouck, and J. Geeraerts. 2005. Field measurements of wave overtopping at the rubble mound breakwater of Rome-Ostia yacht harbor, Coastal engineering, 52(12), 1155-1174.

Buccino, M., D. Vicinanza, D. Salerno, D. Banfi, and M. Calabrese. 2015a. Nature and magnitude of wave loadings at Seawave Slot-cone Generators, Ocean Engineering, 95, 34-58.

Buccino, M., D. Stagonas, and D. Vicinanza. 2015b. Development of a composite sea wall wave energy converter system, Renewable Energy, 81, 509-522.

Buccino, M., D. Banfi, D. Vicinanza, M. Calabrese, G. Del Giudice, and A. Carravetta. 2012. Non Breaking wave forces at the front face of seawave slotcone generators, Energies, 5(11), 47794803.

Burman, K., and A. Walker. 2009. Ocean Energy Technology Overview, U.S. Department of Energy, Office of Energy Efficiency and Renewable Energy, Federal Energy Management Program.

Contestabile, P., V. Ferrante, and D. Vicinanza. 2015. Wave Energy Resource along the Coast of Santa Catarina (Brazil), Energies 8(12), 14219-14243.

Contestabile, P., V. Ferrante, E. Di Lauro, and D. Vicinanza. 2016. Prototype overtopping breakwater for wave energy conversion at port of Naples, Proceeding of the Twenty-sixth International Ocean and Polar Engineering Conference, Rhodes, Greece, 616-621. 
Contestabile, P., C. Iuppa, E. Di Lauro, L. Cavallaro, T. Lykke Andersen, and D. Vicinanza, 2017 a. Wave loadings acting on innovative rubble mound breakwater for overtopping wave energy conversion, Coastal Engineering, 122, 60-74.

Contestabile, P., E. Di Lauro, M. Buccino, and D. Vicinanza. 2017b. Economic assessment of Overtopping BReakwater for Energy Conversion (OBREC): a case study in Western Australia, Sustainability, 9(1), 51.

EurOtop, Wave overtopping of sea defences and related structures: Assessment manual. 2007. N.W.H. Allsop, T. Pullen, T. Bruce, J.W. Van der Meer, H. Schüttrumpf, A. Kortenhaus. (www.overtopping-manual.com)

Falcão, A.F.d.O., and J. Henriques. 2016. Oscillating-water-column wave energy converters and air turbines: A review, Renewable Energy, 85, 1391-1424.

Gunn, K. and C. Stock-Williams. 2012. Quantifying the global wave power resource, Renewable Energy, 44, 296-304.

Herbert D.M. 1995. The overtopping of seawalls, a comparison between prototype and physical model data, Report SR 448, HR Wallingford, Wallingford, UK.

Iuppa, C., P. Contestabile, L. Cavallaro, E. Foti, and D. Vicinanza. 2016. Hydraulic Performance of an Innovative Breakwater for Overtopping Wave Energy Conversion, Sustainability, 8, 1226.

Kofoed, JP. 2002. Wave Overtopping of Marine Structures: Utilization of wave energy, Ph.D. thesis, Hydraulics \& Coastal Engineering Laboratory, Department of Civil Engineering, Aalborg University, Denmark, $171 \mathrm{pp}$.

Kortenhaus, A., J. Pearson, T. Bruce, N.W.H. Allsop, and J.W. Van der Meer. 2003. Influence of parapets and recurves on wave overtopping and wave loading of complex vertical walls, Proceeding of Coastal Structures 2003, 369-381.

Margheritini, L., D. Vicinanza, and P. Frigaard. 2009. SSG wave energy converter: design, reliability and hydraulic performance of an innovative overtopping device, Renewable Energy, 34, 13711380 .

Medina-Lopez, E., N.W.H. Allsop, A. Dimakopoulos, and T. Bruce. 2015. Conjectures on the Failure of the OWC Breakwater at Mutriku, Proceedings of Coastal Structures and Solutions to Coastal Disasters Joint Conference, Boston, Massachusetts.

Mørk, G., S. Barstow, A. Kabuth, and M.T. Pontes. 2010. Assessing the global wave energy potential, Proceeding of the $29^{\text {th }}$ International Conference on Ocean, Offshore and Arctic Engineering, ASME 2010, 447-454

Oliveira, P., F. Taveira-Pinto, T. Morais, and P. Rosa-Santos. 2016. Experimental evaluation of the effect of wave focusing walls on the performance of the Sea-wave Slot-cone Generator, Energy Conversion and Management, 110, 165-175.

Pearson, J., T. Bruce, N.W.H. Allsop, A. Kortenhaus, and J. van der Meer. 2004. Effectiveness of recurve walls in reducing wave overtopping on seawalls and breakwaters, Proceeding of 29 International Coastal Engineering Conference, ASCE, 29 (4), 4404-4416.

Pullen T., W. Allsop, T. Bruce, and J. Pearson. 2009. Field and laboratory measurements of mean overtopping discharges and spatial distributions at vertical seawalls, Coastal Engineering, 56(2), 121-140.

Takahashi, S., H. Nakada, H. Ohneda, and M. Shikamori. 1992. Wave power conversion by a prototype wave power extracting caisson in Sakata port, Proceedings of $23^{\text {rd }}$ International Conference on Coastal Engineering, ASCE, 3440-3453.

Torre-Enciso, Y., I. Ortubia, L.I. Lopez de Aguileta, and J. Marques. 2009. Mutriku wave power plant: from the thinking out to the reality, Proceeding of the $8^{\text {th }}$ European Wave Tidal Energy Conference, Uppsala, Sweden, 319-329.

Torre-Enciso, Y., J., Marques, and L.I. Lopez de Aguileta. 2010. Mutriku: Lessons learnt, Proceeding of the $3^{\text {th }}$ International Conference on Ocean Energy, Bilbao.

Troch P., J. Geeraerts, B. Van de Walle, J. De Rouck, L. Van Damme, W. Allsop, and L. Franco. 2004. Full-scale wave overtopping measurements on the Zeebrugge rubble mound breakwater, Coastal Engineering, 51, 609-628.

Van Doorslaer, K. and J. De Rouck. 2011. Reduction on Wave Overtopping on a Smooth Dike by Means of a Parapet, Coastal Engineering Proceedings, 1(32), p.6.

Vicinanza, D., L. Cappietti, V. Ferrante, and P. Contestabile. 2011. Estimation of the wave energy in the Italian offshore, Journal of Coastal Research, 64, 613-617. 
Vicinanza, D., J.H. Nørgaard, P. Contestabile, and T. Lykke-Andersen. 2013a. Wave loadings acting on overtopping breakwater for energy conversion, Journal of Coastal Research, Special Issue 65, 1669-1674.

Vicinanza, D., P. Contestabile, and V. Ferrante. 2013b. Wave energy potential in the north-west of Sardinia (Italy), Renewable Energy, 50, 506-521.

Vicinanza, D., P. Contestabile, J. Nørgaard, and T. Lykke-Andersen. 2014. Innovative rubble mound breakwaters for overtopping wave energy conversion, Coastal Engineering, 88, 154-170.

Zanuttigh, B., and J.W. van der Meer. 2008. Wave reflection from coastal structures in design conditions, Coastal engineering, 55, 771-779. 